\title{
How Can Steering Committees Manage Change Through Dynamic Capabilities to Increase System Satisfaction?
}

\author{
Kris Murphy \\ Case Western Reserve \\ University, \\ Cleveland, Ohio, United States \\ kam31@case.edu
}

\author{
Kalle Lyytinen \\ Case Western Reserve \\ University, \\ Cleveland, Ohio, United States \\ kj113@case.edu
}

\author{
Toni Somers \\ Wayne State University, \\ Detroit, MI, United States \\ toni_somers@wayne.edu
}

\begin{abstract}
Enterprise-wide system implementations require organizations to think differently about how they approach project-based IT governance. Companies typically use executive steering committees to govern IT projects; yet, problems with user satisfaction linger. While scholars and practitioners have some understanding of what make steering committees successful, we do not fully understand what capability levers are available. This study contributes to the limited research on how project-based IT governance can manage change to achieve higher satisfaction with system usage. We find that steering committees can be more effective by stacking business IS capability with powerful antecedents of innovative culture and capable champions. Second, we find that business IS competence mediates the effects of innovative culture and capable champions on system quality. Third, we take a step forward in developing a change model based on dynamic capability for IT governance. We suggest several implications for practice and theory of project-based IT governance.
\end{abstract}

\section{Introduction}

Use of steering committees to organize and govern complex system implementations has evolved over the years. As an executive IT governance vehicle, steering committees are a critical factor in enterprise implementation success and IT sophistication [1-3]. A steering committee exhibits a form of project-based IT governance which involves prudent executive control for IS project management and enacts a valid "social process" to involve stakeholders [4, p. 215]. While some research on executive IT governance in the form of steering committees exists, in agreement with Kirsch, we argue that "desired outcomes, standards, and corrective actions are not always obvious" in IT implementations hinting towards a "broader interpretation" of project-based IT governance [4, p. 216]. For example, existing studies have so far failed to incorporate the impact of change culture and change champions in explaining system usage. Moreover, understanding of associated change capabilities and project-based IT governance is inadequate [5-7].

The extant literature and IT Governance Institute broadly define executive IT governance (e.g. corporate boards, steering committees) as a vital component of enterprise governance consisting of organizational and leadership processes, which are concerned with implementing processes, the definition of said processes and creation of mechanisms to support strategic alignment between businesses and IT $[5,8-$ 10]. While the literature supports that steering committees are a judicious IT governance mechanism, they can also be empowered change agents $[2,5,11$, 12]. The steering committee environment is a social system, so the quality of their role depends heavily on the interactions that take place within the crossfunctional, cultural milieu. Organizational initiatives, such as project-based IT governance, fail to take root unless implemented with concerted effort to appropriately alter organizational processes due to cultures which are not accepting of innovation. Whereas a culturally inspired system implementation engenders innovation and "the practices that encourage that behavior" [13, p. 128]

Steering committees are in a unique position to drive change across functions, because they consist of high-level, cross-functional managers who are brought together to support the execution of an enterprise project [2, 14]. Research also shows that those who hold top management positions drive strategic change and possess the ability to bring forth organizational change [15-17]. According to Somers and Nelson, a steering committee fulfills a leadership role by offering guidance on allocation, coordination, and enlisting 
support across an organization [14]. While research on steering committee capability has made some steps forward, little is known of how management groups manage change. There is inadequate empirical research on the role of change champions and innovative culture and their respective impacts on project-based IT governance. Current literature is grounded in but a few studies of the structure and internal procedures of steering committees and related capabilities $[2,5,6$, $11,12,18]$. A separate body of knowledge addresses the role of leadership and change management, but none of these studies link change capability to IT governance. Yet, while analyzing an IT governance context, Pult and Manwani argue that "the capability of managing business change increases the efficiency of IT governance" [7, p. 390]. We want to extend this line of research by looking into the factors that contribute to improved systems satisfaction through dynamic change capabilities. In particular, we ask the following research questions:

1. Can executive IT governance within steering committees use social levers of innovative culture and capable champions to affect systemusage?

2. Does having capable change managers an innovative culture enrich business IS competence and promote improved project outcomes?

In setting out our research, we focus on project outcomes defined as whether project goals were met and effective, delivered on time, inside desired budget limits and lead to adequate user adoption when measured by system usage [1, 19-23]. We utilize the resource-based view of the firm (RBV) throughout our investigation because this theory defines how managers can be organized based on a capability to create effective IT governance; thus, it creates a useful lens to analyze project outcomes [24, 25]. RBV broadens conceptions about corporate governance and explains how an innovative culture and change champions contribute to project success [26]. These combined theories, integrated in Figure 1, are used to explain project success outcomes: system quality and satisfaction with system usage [21, 23, 27].

The next sections of this paper are as follows: first, we conduct a literature review on theories of the RBV, enterprise systems project success, and organizational theories on project-based IT governance. Second, we construct a research model and posit several hypotheses, which blend RBV theory with IT project success. Third, we delineate research design, and create scales for proposed constructs and report sample and statistical analyses, Last, we synthesize our findings and discuss the study's shortcomings and review practical implications and future research.

\section{Theoretical Foundations}

We examine research on the following topics: 1) resource-based view; 2) enterprise system project success; 3) steering committee governance. We propose the following theoretical framework (Figure 1). We ground our reviews on multiple reference databases, scholarly search engines, and thorough review of several leading information systems (IS) journals. The key phrases and keywords we used while conducting our search were: "resource-based view", "socio-technical", "change champion", "change management", "steering committee", "IT governance", "IT success", "dynamic capability", "project success" and "change culture". Fifteen articles mentioned steering committees or executive project-based IT governance functions. The lack of research was a recurring point in identified articles [1, 2, 6, 28-30]. Currently, there is little research linking change capability and executive-level project-based IT governance.

Figure 1. The ore tical frame work

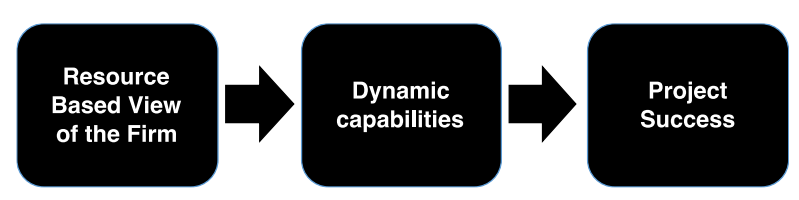

\subsection{Resource-Based Vie w of the Firm}

We leverage the RBV, which advocates that resources can be organized "to produce one or several firm capabilities" to improve "performance" which we define as project success [31, p.894]. In agreement with Judge and Elenkov, the RBV's most influential capabilities are the dynamic capabilities because they "adapt" to opportunities which may be presented by enterprise endeavors which promise improved strategic alignment to systems and corporate goals. Organizations having "dynamic capability thus reflect an organization's ability to achieve new and innovative forms" which can enhance project-based IT governance structures [32, p. 516, 33, 34]. We introduce innovative culture and capable champions as dynamic capabilities from the organizational capacity for change framework that Judge and Elenkov propose [31]. From a project-based IT governance perspective and the capabilities required to be successful, we include the business IS competence capability to link these powerful dynamic capabilities to project success [21]. 


\subsection{Enterprise system project success}

We adopt here Fisk et al.'s [21] governance effectiveness measures, which identify important success dimensions system quality and satisfaction with system use. Success, when created by steering committees in a resource-based framework, spans all dimensions of the time-effort-cost triangle and includes systemquality and system usage [3, 35-37].

System quality. Implemented system quality is a key to project success when generated correctly. Saarinen, et al., argue that quality originates from the perspective of the user [23]. Part of Saarinen's model assesses the success of a project by assessing the quality of the information from the system product, along with various related services [23, 38].

Satisfaction with system usage. Success is also measured by users' satisfaction with system use. User satisfaction measures information system success in terms of "characteristics of the interaction of the user with the system" [21, p. 5, 23, 38]. Bailey and Pearson argued early on that user satisfaction combines all reactions - "positive and negative" - to the information system's factors that affect success [39, p.531].

\subsection{Ste ering committee governance}

Steering committees now frequently appear as part of best practices in guides for project management [18, 40, 41]. A steering committee is viewed as an instrumental governance mechanism which adds to sophistication of IT governance, and subsequently forms a key success factor [2, 6, 35]. Due to the importance of enterprise projects they often engage an executive steering group to oversee such projects $[8$, $10,42]$. The current research on steering committees concentrates on governance practices and functions, IT planning, and resource allocation aspects of such committees. Conversely, there is little research on the change capability aspect of such committees [6, 4345]. Lechler and Cohen accordingly remind us that there is room to expand current understanding of steering committees [6]. Furthermore, some empirical research links steering group activities with business IS competencies as a required condition to achieve success $[5,8]$.

\section{Research Model and Hypotheses}

Overall, we posit that steering committees can promote project success by the inclusion of dynamic capability. Without capable governance, business IS competency (BISC), innovative culture (IC), and capable champions (CC) steering groups will be challenged to achieve implementation successsatisfaction with system quality (SSQ) and satisfaction with system usage (SSU). Therefore, we propose the following research model (Figure 2):

Figure 2. Research model

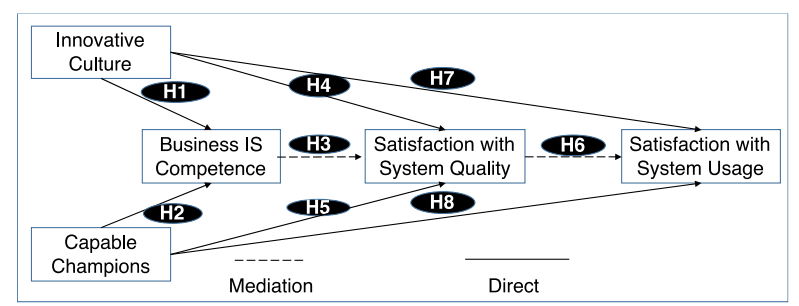

We hypothesize that the change capability constructs of IC and $\mathrm{CC}$ are critical and positive antecedents to BISC. Having a change capabilities underpinning increases the SCs willingness to build BISC.

Hypothesis 1. IC is positively related to BISC.

Hypothesis 2. CC is positively related to BISC.

We further hypothesize that and that, BISC positively mediates the effects of IC and CC on SSQ.

Hypothesis 3a. BISC positively mediates the relationships between IC and SSQ.

Hypothesis 3b. BISC positively mediates the relationships between CC and SSQ.

Likewise, we propose that a steering committee with an innovative culture will have a positive effect on systemquality. Thus, we posit:

Hypothesis 4. IC is positively related to SSQ.

We also posit that having a steering committee with capable champions positively affects system quality.

Hypothesis 5. CC is positively related to SSQ.

A steering committee that produces greater system quality is able to positively mediate the effects of IC, $\mathrm{CC}$, and BISC on satisfaction with systemusage.

Hypothesis 6a. SSQ positively mediates the relationships between IC and SSU.

Hypothesis 6b. SSQ positively mediates the relationships between $C C$ and $S S U$.

Hypothesis 6c. SSQ positively mediates the relationships between BISC and SSU.

A steering committee with a greater cultural tendency to innovate will have higher levels of satisfaction with systemusage. Thus: 
Hypothesis 7. IC is positively related to SSU.

Per our theoretical underpinnings, we propose that having capable champions on a SC will result in higher levels of satisfaction with system usage because they are vested participants who can relate to the users. We propose:

Hypothesis 8. CC is positively related to SSU.

\section{Research Design and Methods}

We conducted a quantitative survey to validate the research model by collecting data from steering committee participants who have recently guided an enterprise systems implementation.

\subsection{Construct operationalization}

Due to the limited research on project-based steering committees, we followed DeVellis [46] to systematically develop constructs and scale by using informational interviews, peer reviews, Q-sort, and pre- and pilot tests. We adapted established scales with modifications to reflect an enterprise steering committee context. All scales use a five-point Likert scale ranging from "strongly disagree" to "strongly agree."

Project success was modeled using two reflective constructs that measure SSQ and SSU. We adapted these two constructs from Fisk et al. [47] which is founded on DeLone and McLean's [38] research and Saarinen's [23] construct and the results of our qualitative study including a pretest and think-aloud session [48]. SSQ was modeled using 7 indicators and SSU was modeled using eight indicators.

IC was modeled as a reflective construct with two indicators based on work of Judge and Douglas [49]. IC measures "the ability of the organization to establish norms of innovation and encourage" change and is drawn from the work of Kotter and Heskett [49, p. $638,50,51]$. CC was modeled as a reflective construct with six indicators based on the construct developed by Judge and Douglas and based on the work of Kanter [49, 52].

BISC was modeled as a reflective construct with five indicators from of Fisk et al. [47] which is based on the work of Bassellier, Benbasat, and Reich [53]. BISC measures a steering committee's ability to "acquire and apply IS knowledge effectively" [21, p. $3]$.

\subsection{Social desirability}

Since limited work exists with regards to IT steering committees, and we used a mono-method approach, we designed ex-ante procedures to avoid common method bias (CMB) [54]. In addition, we nested within the survey measures of social desirability to control for $\mathrm{CMB}$, which improves our ability to detect CMB over that of an unmeasured common latent factor. We chose Hays, Hayashi, and Stewart's 5-item scale (i.e. SDRS-5) [55, 56].

\subsection{Controls and demographics}

Controls were selected based on prior IS and steering committee research and the degree of significance in these prior studies $[1,5,57,58]$. We controlled for solution type-packaged versus proprietary and implementation methodology.

\subsection{Data collection}

Data collection was facilitated through Qualtricsan online survey research tool-over a three-month period from November 2014 to January 2015. Qualifying questions within the survey ensured that only enterprise systems steering committee participants continued past the introduction. The unit of analysis is an engaged, project-based steering committee. The survey respondents were asked to participate only if they had served on a steering committee with in the last three years. Data was obtained from multiple steering committee roles that were previously identified through our literature review, qualitative and quantitative studies [1, 59]. Participants were recruited through the primary researcher's network of information system practitioners, executives, researchers, and alumni of two notable consulting firms which are known for implementing enterprise software. Candidates were identified through a careful process of resume review that was available on the alumni network and LinkedIn to ensure that they held a key position. The survey candidates had titles of project/program manager, program director, IT director, VP, CIO, CFO, CEO, senior manager, senior director of leadership. 164 steering committee participants provided usable responses resulting in an effective response rate of $4.1 \%$. Sample demographics for the data are shown in Tables 1 and 2.

Table 1. Sa mple : Organization size

\begin{tabular}{llrr} 
Item & Size of Organization & Number & Percent \\
\hline 1 & Greater than \$25 billion & 29 & $17.7 \%$ \\
2 & Between $\$ 5$ billion and \$24 billion & 55 & $33.5 \%$ \\
3 & Between \$1 billion and \$4.9 billion & 32 & $19.5 \%$ \\
4 & Under \$1 billion & 30 & $18.3 \%$ \\
5 & Private & 18 & $11.0 \%$ \\
& Total & 164 & $100.0 \%$ \\
\hline
\end{tabular}


Table 2. Sample: Education le vel

\begin{tabular}{clrr} 
Item & Highest Level of Education & Number & Percent \\
\hline 1 & Associate's degree & 5 & $3 \%$ \\
2 & Bachelor's degree & 51 & $31 \%$ \\
3 & Master's degree (e.g. MBA, MS or other) & 95 & $58 \%$ \\
4 & PhD & 8 & $5 \%$ \\
5 & High school diploma & 5 & $3 \%$ \\
& Total & 164 & $100 \%$ \\
\hline
\end{tabular}

Due to the nature of these boards and the frequency at which enterprise projects are undertaken, it was quite challenging to find steering committee participants. Unlike corporate boards, there are no governing bodies for steering committees. When we did identify someone, they tended to have served on multiple steering committees -5.5 on average. Only $6 \%$ indicated that their highest level of education was an Associate's degree or high school diploma. Most of the respondents held at least a Master's degree (63\%).

\subsection{Data analysis}

The hypothesized relationships among constructs were analyzed using consistent partial least squares algorithm (PLSc) and SmartPLS application version 3.2.4. The decision to use PLSc, rather than a covariance-based structured equation model (SEM) was based primarily on the nature of the study, limited sample size, and inclusion of consistent analysis methods within the newer version of the product which produces similar results to a covariance-based SEM tool using a nomological network. Lacking theories that apply directly to a steering committee makes PLSc a suitable parameter estimation methodology [60, 61].

\subsection{Exploratory factor analysis}

An exploratory factor analysis (EFA) was performed to explore the extent to which the indicators meet the a priori expectations of factorability (see Table 3). Most items loaded on their respective factors with values greater than 0.50 , considered to be the minimum conservative value for practical significance and in cases where the threshold was not met the items were removed and are discussed next [62]. All remaining items cross-loaded with differences from the value of the loading on the primary factor by more than 0.20 , indicating sufficient discriminate validity. Cronbach's alphas were above the 0.70 threshold recommended by Hair et al. [62]. As a result of the new PLSc algorithm, we identified some indicators that needed to be removed to improve the nomological model. We removed three indicators from $\mathrm{CC}$ because they loaded below 0.50 and negatively affected construct reliability. Four indicators were removed from SSU because they loaded below 0.50. One indicator was removed from SSQ because it significantly loaded below 0.50 .

Table 3. EFA measure ment model re sults

\begin{tabular}{cccc} 
Construct & \# of Items & Loadings $>0.5$ & $\begin{array}{c}\text { Cronbach } \\
\text { 's Alpha's } \\
>.0 .7\end{array}$ \\
\hline Innovative Culture & 2 & $.916, .801$ & 0.847 \\
Capable Champions & 3 & $0.614,0.812,0.712$ & 0.760 \\
Satifaction with System & 6 & $0.761,0.744,0.615,0.722,0.781$, & 0.869 \\
Quality & 0.706 & 0.810 \\
Satifaction with System Use & 4 & $0.747,0.738,0.653,0.738$ & 0.853 \\
Business IS Competence & 5 & $0.716,0.73,0.681,0.792,0.729$ & \\
\hline
\end{tabular}

\subsection{Confirmatory factor analysis}

Next, we a conducted confirmatory factor analys is to evaluate the validity of the initial measurement model. The initial analysis addressed the factorial validity of the reflective constructs. The significance of parameters was assessed using asymptotic t-statistics generated by resampling techniques [60, 63, 64]. SmartPLS enables this operation by its consistent bootstrapping procedures in which we tested using 5,000 subsamples. In addition, we assessed CMB, which is discussed before the structural model analys is.

We tested for convergent validity of the factors using three tests recommended by Fornell and Larker and new criterion presented by Henseler, Ringle, and Sarstedt for the use of PLSc [65, 66]: item reliability, composite reliability, average variance extracted (AVE), and Heterotrait-Monotrait Ratio (HTMT). All items demonstrated standardized loadings on their respective factors greater than 0.50, demonstrating item reliability [62]. Composite reliability for each of the five reflective constructs was greater than 0.70 , indicating internal consistency [62]. For each of the five factors, AVE was greater than 0.50; the minimum threshold recommend by Hair et al. [62]. Discriminate validity is demonstrated when if the HTMT value is below 0.90 or the more conservative 0.85 criterion (See Table 4) [65]. A summary of our test results and the correlation matrix are shown in Table 4.

Table 4. Tests of Discriminate Validity and He te rotrait-Mo notrait Ratio

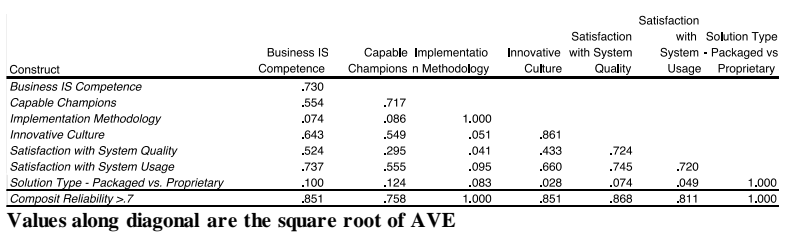

\subsection{Common me thod bias}

We tested for CMB by comparing standardized regression weights of factor loadings with and without a marker variable [54]. The differences in factor 
loadings in the models with and without the marker variable were all significantly less than 0.20 , indicating the lack of meaningful CMB. Moreover, examination of the correlations between the latent variables does not indicate significant concern. All correlation values are well below the suggested maximum threshold of 0.90 [67]. All method factor path coefficients are not statistically significant. Hence, the method effects are unlikely to be a significant concern for our study. Therefore, we chose to remove the social desirability construct from the final structural equation model.

\subsection{Structural model analysis}

Because our structural model is complex with many indicators, our matched sample size of 164 is small given the complexity of our model [67]. Mediation effects were checked using a product-ofcoefficients test [68]. The mediation effects were tested using MacKinnon et al. [69] procedures to calculate asymmetric confidence intervals on the product of two mediation path coefficients (i.e., Sobel test). In addition, we used the Preacher and Hayes bootstrapping test to confirm the significance of the observed mediation effects [70]. The total effects of each factor on SSU range between 0.246 and 0.558 . The dynamic capability factors had total effects of IC 0.494, CC 0.289 and BISC 0.246.

A summary of hypothesis test results is provided in Table 5 .

\section{Table 5. Summary of research hypotheses}

\begin{tabular}{|c|c|c|}
\hline Hypotheses & $\begin{array}{c}\text { Path Coefficient \& p } \\
\text { Value }\end{array}$ & $\begin{array}{c}\text { Supporte } \\
\text { d? }\end{array}$ \\
\hline $\mathrm{H} 1$ & $0.484, p<0.000$ & Yes \\
\hline $\mathrm{H} 2$ & $\begin{array}{c}0.297, p<0.003 \\
\mathrm{P} 1: 0.484, p<0.000 \mathrm{P} 2:\end{array}$ & Yes \\
\hline $\mathrm{H} 3 \mathrm{a}$ & $\begin{array}{c}0.440, p<0.002 \text { Sobel: } \\
p<0.009 \\
\text { P1: 0.297, } p<0.003 \text { P2: }\end{array}$ & Yes \\
\hline $\mathrm{H} 3 \mathrm{~b}$ & $\begin{array}{c}0.440, p<0.002 \text { Sobel: } \\
p<0.031\end{array}$ & Yes \\
\hline $\mathrm{H} 4$ & $0.172, p<0.241$ & No \\
\hline $\mathrm{H} 5$ & $-0.041, p<0.758$ & No \\
\hline $\mathrm{H} 6 \mathrm{a}$ & $\begin{array}{c}\mathrm{P} 1: 0.172, p<0.241 \mathrm{P} 2: \\
0.558, p<0.000 \text { Sobel: } \\
p<0.247\end{array}$ & No \\
\hline $\mathrm{H} 6 \mathrm{~b}$ & $\begin{array}{c}\text { P1: }-0.041, p<0.758 \text { P2: } \\
0.558, p<0.000 \text { Sobel: } \\
p<0.760 \\
\text { P1: } 0.440, p<0.002 \text { P2: }\end{array}$ & No \\
\hline $\mathrm{H} 6 \mathrm{c}$ & $\begin{array}{c}0.558, p<0.000 \text { Sobel: } \\
p<0.004\end{array}$ & Yes \\
\hline $\mathrm{H} 7$ & $0.279, p<0.009$ & Yes \\
\hline $\mathrm{H} 8$ & $0.239, p<0.032$ & Yes \\
\hline
\end{tabular}

The structural model results, with path coefficients, is presented in Figure 3.
Figure 3. Structural model results

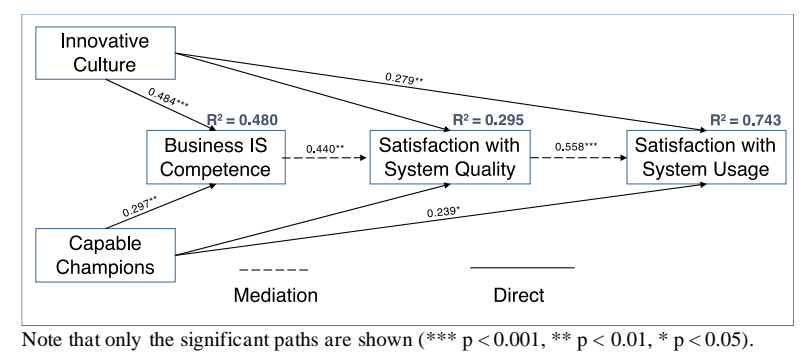

\section{Discussion}

Project-based IT governance in the form of steering committees or corporate boards can be a critical success factor for enterprise system implementations. Research suggests that having these project-based governance bodies increases IT sophistication. Yet, not much is understood in terms of the dynamics of this governance function and how project outcomes can be positively affected. Given the complexity of implementing modern technologies, we argue that dynamic change enabled, project-based IT governance is required.

We found that having an innovative culture and capable champions on a steering committee does have a direct and positive influence on BISC and SSU and a mediated effect on SSQ. The mediated effect means that senior managers are more motivated to build BISC and achieve high system quality through oversight if they have a higher stake in the project. Satisfaction with system usage increases because the steering committee is organized based on dynamic capability to drive change and improve processes. The $\mathrm{R} 2$ value of 0.743 for SSU indicates that the model explains a substantial amount of variance. The two factors with the highest total effects on SSU were IC at 0.494 and SSQ at 0.558 .

In agreement with Jewer and McKay, we found that BISC is a significant indicator of good IT governance and does impact performance through its direct affect on SSQ and indirect effect on SSU. Having SC managers with no IS implementation knowledge places an extra burden on the expanded project team [8]. Surprisingly, we found that there is no direct effect of change capability on system quality (i.e. SSQ is not directly impacted by IC or CC). We feel that this insignificance is due to the importance of BISC on the traditional measure of system quality in terms of meeting the requirements of the system which, unlike SSU, may not require direct input from IC and CC.

Based on our findings, we feel that project-based IT governance steering committees must be designed with dynamic change capability in mind. Reliance on 
typical project management levers may mean that the project is headed in the wrong direction.

\section{Limitations and Future Research}

This study is limited due to the lack of preexisting research and proven constructs in a steering committee context. Our study is also limited in that we only captured one level of respondents from a project team. Our research moves a step forward in our understanding of steering committee capability and design but is limited by sample size. Additional research is required to further the development of other capabilities that may influence project success. Furthermore, research is required to build a change model that is valid across multiple levels.

[1] Murphy, K., Lyytinen, K., and Somers, T.M., "Does Steering Committee Information Processing Capacity Influence Project Success in Enterprise-Wide System Implementations - a Field Study", HICSS49: Hawaii International Conference on System Sciences, 49(2016, pp. 10.

[2] Karimi, J., Bhattacherjee, A., Gupta, Y.P., and Somers, T.M., "The Effects of Mis Steering Committees on Information Technology Management Sophistication", Journal of Management Information Systems, 17(2), 2000, pp. 207-230.

[3] Somers, T.M., and Nelson, K.G., "The Impact of Critical Success Factors across the Stages of Enterprise Resource Planning Implementations", in (Editor, 'ed.'^'eds.'): Book The Impact of Critical Success Factors across the Stages of Enterprise Resource Planning Implementations, IEEE, 2001, pp. 10 pp.

[4] Kirsch, L.S., "Portfolios of Control Modes and Is Project Management", Information systems research, 8(3), 1997, pp. 215-239.

[5] Murphy, K., A Theory of Steering Committee Capabilities for Implementing Large Scale EnterpriseWide Information Systems, Case Western Reserve University, 2016.

[6] Lechler, T.G., and Cohen, M., "Exploring the Role of Steering Committees in Realizing Value from Project Management", Project management journal, 40(1), 2009, pp. 42-54.

\section{Conclusion and Implications for Practice}

This research opens a new dimension to our understanding of how steering committees can operate more effectively. Our findings have implications for both practitioners. For the practitioner, design of their committee should consider the dynamic change forces that are required for implementation success. We recommend that organizations carefully consider the impact of project-based IT governance and implications of each steering committee role relative to the degree of business IS competency required and the amount of change impacting the organization.

\section{References}

[7] Pult, S., and Manwani, S., "Evaluating the Interdependencies between Managing Business Change, It Sourcing and It Governance", in (Editor, 'ed.'^'eds.'): Book Evaluating the Interdependencies between Managing Business Change, It Sourcing and It Governance, Academic Conferences Limited, 2013, pp. 387.

[8] Jewer, J., and Mckay, K.N., "Antecedents and Consequences of Board It Governance: Institutional and Strategic Choice Perspectives", Journal of the Association for Information Systems, 13(7), 2012, pp. 581 .

[9] Institute, I.G., "Board Briefing on It Governance (2nd Ed)", in (Editor, 'ed.'^'eds.'): Book Board Briefing on It Governance (2nd Ed), 2003

[10] De Haes, S., and Van Grembergen, W., "It Governance Structures, Processes and Relational Mechanisms: Achieving It/Business Alignment in a Major Belgian Financial Group", in (Editor, 'ed.'^'eds.'): Book It Governance Structures, Processes and Relational Mechanisms: Achieving It/Business Alignment in a Major Belgian Financial Group, IEEE, 2005, pp. 237b-237b.

[11] Gupta, Y.P., and Raghunathan, T., "Impact of Information Systems (Is) Steering Committees on Is Planning*", Decision sciences, 20(4), 1989, pp. 777793.

[12] Slater, D., "The Hidden Costs of Enterprise Software: It Budgeting", CIO-FRAMINGHAM MA-, 11(1998, pp. 48-55.

[13] Kotter, J.P., Force for Change: How Leadership Differs from Management, Simon and Schuster, 2008. 
[14] Somers, T.M., and Nelson, K.G., "The Impact of Strategy and Integration Mechanisms on Enterprise System Value: Empirical Evidence from Manufacturing Firms", European Journal of Operational Research, 146(2), 2003, pp. 315-338.

[15] Boeker, W., "Strategic Change: The Influence of Managerial Characteristics and Organizational Growth", Academy of Management Journal, 40(1), 1997, pp. 152-170.

[16] Wiersema, M.F., and Bantel, K.A., "Top Management Team Demography and Corporate Strategic Change", Academy of Management Journal, 35(1), 1992, pp. 91-121.

[17] Beath, C.M., "Supporting the Information Technology Champion", MIS quarterly, 1991, pp. 355372.

[18] Nolan, R.L., Managing Information Systems by Committee, Reprint Service, Harvard Business Review, 1982.

[19] Jiang, J.J., Klein, G., and Pick, R.A., "The Impact of Is Department Organizational Environments Upon Project Team Performances", Information \& Management, 40(3), 2003, pp. 213-220.

[20] Procaccino, J.D., and Verner, J.M., "Software Project Managers and Project Success: An Exploratory Study", Journal of Systems and Software, 79(11), 2006, pp. 1541-1551.

[21] Fisk, A., Berente, N., and Lyytinen, K., "Boundary Spanning Competencies and Information System Development Project Success", in (Editor, 'ed.'^'eds.'): Book Boundary Spanning Competencies and Information System Development Project Success, 2010, pp. 96.

[22] Delone, W.H., "The Delone and Mclean Model of Information Systems Success: A Ten-Year Update", Journal of Management Information Systems, 19(4), 2003, pp. 9-30.

[23] Saarinen, T., "An Expanded Instrument for Evaluating Information System Success", Information \& Management, 31(2), 1996, pp. 103-118.

[24] Trist, E., "The Evolution of Socio-Technical Systems", Occasional paper, 2(1981, pp. 1981.

[25] Lyytinen, K., and Newman, M., "Explaining Information Systems Change: A Punctuated Socio-
Technical Change Model", European Journal of Information Systems, 17(6), 2008, pp. 589-613.

[26] Bailey, B.C., Decision Making in the Corporate Boardroom: Designing the Conditions for Effectiveness, Case Western Reserve University, 2012.

[27] Baroudi, J.J., and Orlikowski, W.J., "A ShortForm Measure of User Information Satisfaction: A Psychometric Evaluation and Notes on Use", Journal of Management Information Systems, 4(4), 1988, pp. 44-59.

[28] Doll, W.J., and Torkzadeh, G., "The Relationship of Mis Steering Committees to Size of Firm and Formalization of Mis Planning", Communications of the ACM, 30(11), 1987, pp. 972-978.

[29] Mosavi, A., "Exploring the Roles of Portfolio Steering Committees in Project Portfolio Governance", International Journal of Project Management, 32(3), 2014, pp. 388-399.

[30] Zwikael, O., Pathak, R.D., Singh, G., and Ahmed, S., "The Moderating Effect of Risk on the Relationship between Planning and Success", International Journal of Project Management, 32(3), 2014, pp. 435-441.

[31] Judge, W.Q., and Elenkov, D., "Organizational Capacity for Change and Environmental Performance: An Empirical Assessment of Bulgarian Firms", Journal of Business Research, 58(7), 2005, pp. 893-901.

[32] Teece, D.J., Pisano, G., and Shuen, A., "Dynamic Capabilities and Strategic Management", Strategic Management Journal, 18(7), 1997, pp. 509-533.

[33] Wernerfelt, B., "The Resource-Based View of the Firm: Ten Years After", Strategic Management Journal, 16(3), 1995, pp. 171-174.

[34] Erickson, J.M., and Ranganathan, C., "Project Management Capabilities: Key to Application Development Offshore Outsourcing", in (Editor, 'ed.'^'eds.'): Book Project Management Capabilities: Key to Application Development Offshore Outsourcing, IEEE, 2006, pp. 199b-199b.

[35] Somers, T.M., and Nelson, K.G., "A Taxonomy of Players and Activities across the Erp Project Life Cycle", Information \& Management, 41(3), 2004, pp. 257-278.

[36] Sedera, D., and Gable, G.G., "A Factor and Structural Equation Analys is of the Enterprise Systems 
Success Measurement Model", in (Editor, 'ed.'^'eds.'): Book A Factor and Structural Equation Analys is of the Enterprise Systems Success Measurement Model, As sociation for Information Systems, 2004

[37] Gable, G.G., Sedera, D., and Chan, T., "ReConceptualizing Information System Success: The Is Impact Measurement Model", Journal of the Association for Information Systems, 9(7), 2008,

[38] Delone, W.H., and Mclean, E.R., "Information Systems Success: The Quest for the Dependent Variable", Information systems research, 3(1), 1992, pp. 60-95.

[39] Bailey, J.E., and Pearson, S.W., "Development of a Tool for Measuring and Analyzing Computer User Satisfaction", Management science, 29(5), 1983, pp. 530-545.

[40] Kerzner, H., Advanced Project Management: Best Practices on Implementation, John Wiley \& Sons, 2004.

[41] Englund, R.L., and Bucero, A., Project Sponsorship: Achieving Management Commitment for Project Success, John Wiley \& Sons, 2006.

[42] Parent, M., and Reich, B.H., "Governing Information Technology Risk", California Management Review, 51(3), 2009, pp. 134-152.

[43] Mckeen, J.D., and Guimaraes, T., "Selecting Mis Projects by Steering Committee", Communications of the ACM, 28(12), 1985, pp. 1344-1352.

[44] Hyvari, I., "Success of Projects in Different Organizational Conditions", Project management journal, 37(4), 2006, pp. 31.

[45] Doll, W.J., "Avenues for Top Management Involvement in Successful Mis Development", MIS quarterly, 1985, pp. 17-35.

[46] Devellis, R.F., Scale Development: Theory and Applications, Sage publications, 2012.

[47] Fisk, A., Berente, N., and Lyytinen, K., "Boundary Spanning Competencies and Information System Development Project Success", in (Editor, 'ed.'^'eds.'): Book Boundary Spanning Competencies and Information System Development Project Success, ICIS $2010 \quad$ Proceedings. Paper 96. http://aisel.aisnet.org/icis2010_submissions/9

6, 2010

[48] Bolton, R.N., "Pretesting Questionnaires: Content Analyses of Respondents' Concurrent Verbal Protocols", Marketing Science, 12(3), 1993, pp. 280303.

[49] Judge, W., and Douglas, T., "Organizational Change Capacity: The Systematic Development of a Scale", Journal of Organizational Change Management, 22(6), 2009, pp. 635-649.

[50] Kotter, J.P., Corporate Culture and Performance, Simon and Schuster, 2008.

[51] Heskett, J.L., and Kotter, J.P., "Corporate Culture and Performance", Business Review. Vol, 2(1992, pp. 83-93.

[52] Kanter, R.M., The Change Masters: Binnovation and Entrepreneturship in the American Corporation, Touchstone Book, 1983.

[53] Bassellier, G., Benbasat, I., and Reich, B.H., "The Influence of Business Managers' It Competence on Championing It", Information systems research, 14(4), 2003, pp. 317-336.

[54] Podsakoff, P.M., Mackenzie, S.B., Lee, J.-Y., and Podsakoff, N.P., "Common Method Biases in Behavioral Research: A Critical Review of the Literature and Recommended Remedies", Journal of applied psychology, 88(5), 2003, pp. 879.

[55] Paulhus, D.L., "Socially Desirable Responding: The Evolution of a Construct", The role of constructs in psychological and educational measurement, 2002, pp. 49-69.

[56] Hays, R.D., Hayashi, T., and Stewart, A.L., "A Five-Item Measure of Socially Desirable Response Set", Educational and Psychological Measurement, 49(3), 1989, pp. 629-636.

[57] Agarwal, R., and Prasad, J., "Are Individual Differences Germane to the Acceptance of New Information Technologies?", Decision sciences, 30(2), 1999, pp. 361-391.

[58] Agarwal, R., and Prasad, J., "The Role of Innovation Characteristics and Perceived Voluntariness in the Acceptance of Information Technologies", Decision sciences, 28(3), 1997, 2007, pp. 557-582. 
[59] Murphy, K., Boland, R., "How Do Steering Committees Steer?", in (Editor, 'ed.'^'eds.'): Book How Do Steering Committees Steer?, DSI, Tampa, FL, 2014

[60] Chin, W.W., "Chapter Ten: The Partial Least Squares Approach to Structural Equation Modeling", in (Marcoulides, G.A., 'ed.' Modern Methods for Business Research, Lawrence Erlbaum Associates, Mahwah, NJ, 1998, pp. 295-336.

[61] Haenlein, M., and Kaplan, A.M., "A Beginner's Guide to Partial Least Squares Analysis", Understanding Statistics, 3(4), 2004, pp. 283-297.

[62] Hair, J.F., Black, W.C., Babin, B.J., Anderson, R.E., and Tatham, R.L., Multivariate Data Analysis, Prentice Hall Upper Saddle River, NJ, 2010.

[63] Götz, O., Liehr-Gobbers, K., and Krafft, M., "Chapter 29: Evaluation of Structural Equation Models Using the Partial Least Squares (Pls) Approach", in (Vinzi, V.E., Chin, W.W., Henseler, J., and Wang, H., 'eds.'): Handbook of Partial Least Squares: Concepts, Methods, and Applications, Springer, Heidelberg, Germany, 2010, pp.691-711.

[64] Geffen, D., and Straub, D., "A Practical Guide to Factorial Validity Using Pls-Graph: Tutorial and Annoted Example", Communications of the Association for Information Systems, 16(2005, pp. 91109.

[65] Henseler, J., Ringle, C.M., and Sarstedt, M., "A New Criterion for Assessing Discriminant Validity in Variance-Based Structural Equation Modeling", Journal of the academy of marketing science, 43(1), 2015, pp. 115-135.

[66] Hair, J., Joseph F, Black, W.C., Babin, B.J., Anderson, R.E., and Tatham, R.L., Multivariate Data Analysis, Prentice Hall, Upper Saddle River, NJ, 2010.

[67] Hair Jr, J.F., Hult, G.T.M., Ringle, C., and Sarstedt, M., A Primer on Partial Least Squares Structural Equation Modeling (Pls-Sem), SAGE Publications, Incorporated, 2013.

[68] Wood, R.E., Goodman, J.S., Backmann, N., and Cook, A., "Mediation Testing in Management Research", Organizational research methods, 11(2), 2008, pp. 270-295.

[69] Mackinnon, D.P., Fritz, M.S., Williams, J., and Lockwood, C.M., "Distribution of the Product
Confidence Limits for the Indirect Effect: Program Prodclin", Behavior research methods, 39(3), 2007, pp. 384-389.

[70] Preacher, K.J., and Hayes, A.F., "Asymptotic and Resampling Strategies for Assessing and Comparing Indirect Effects in Multiple Mediator Models", Behavior research methods, 40(3), 2008, pp. 879-891. 